\title{
Extracurricular activities of students - a means of forming professional motivation
}

\author{
Galina Marchenko ${ }^{1 *}$, Sergey Timofeev ${ }^{1}$, and Ksenia Vodopianov $a^{2}$ \\ ${ }^{1}$ Don State Technical University, 344003, 1 Gagarin sq., Rostov-on-Don, Russia \\ ${ }^{2}$ Donetsk National University, 83001, Universitetskaya str., 24, Donetsk, Ukraine
}

\begin{abstract}
The article analyzes the specificities of future teachers' extracurricular activities as a means of forming their professional motivation. The author proves that extracurricular work can be considered as a factor of generating students ' primary interest to the future occupation. The variety and complexity of extracurricular activities allow to reveal the diversity of the world, the job, human relationships and lead to increased motivation for getting professional pedagogical knowledge.
\end{abstract}

\section{Introduction}

The political and social and economic processes that take place in the world nowadays are being carried out at a previously unprecedented speed. To ensure a decent standard of living for mankind, to preserve each state sovereignty, each person's freedom and independence, any country and any society needs to keep up with the ongoing changes and adapt to them in an optimal way. Back in 2018, at the 14th major press conference the President of the Russian Federation expressed the idea that "we need to jump into a new technological order. Without this the country has no future. This is a fundamental question. ... It is necessary to concentrate the available resources, find them and concentrate on the most important areas of development" [1-12]. One of the most important resources that is necessary for the implementation of a technological breakthrough is a Man and his knowledge, competence, experience, relationships. The training of a professional specialist, capable of highly skilled creative working, is one of the main directions that require the concentration of general efforts, the President Putin spoke about. Therefore, the words of the Academician E.V. Bondarevskaya remain still burning: "Education is interaction with the future, since its subject is a growing and a developing person, whose spirituality, morality and business qualities will be fully revealed in a future independent life ..." [1, p. 18]. As the future of each society and each state depends on each person (on the personal and professional ideals, values, relationships, qualities), the issues of professional training in the whole and professional training of future teachers in particular do not lose their extreme relevance.

Our long-term practical experience in teacher-training education and the results of research activities prove that, unfortunately, the social and professional authority of the teaching jobs, lost in the 1990s, has never been restored [6]. The education sector continues

\footnotetext{
*Corresponding author: donpedagog2018@mail.ru
} 
to be perceived as a service sector, but we categorically cannot agree with this definition [7], because such an approach excludes the upbringing component of education, focusing on learning as training and its results. Thus, upbringing and its components often remain beyond the area of university teachers' attention, and do not arouse active interest among the majority of future teachers. Learning and upbringing constitute a single pedagogical process, and insufficient attention to one of its components negatively affects the quality of the holistic educational process. That is why the task of forming a stable interest and professionally oriented motives among future teachers is extremely important to ensure high-quality professional pedagogical training. The science has proven and the practice has confirmed the fact that an employee with persistent internal, socially and personally significant professional motives works more productively than anyone without them.

The concept "motivation" was introduced into scientific usage by A. Schopenhauer. One of the first scientific works devoted to the study of motives is the research of P. Young "Motives and Behavior". K. Levin considers motives as a meaningful characteristic of needs. Russian psychologists A. Leontiev and S. Rubinstein define the motive as a key concept of their theory of activity. S. Rubinstein emphasizes that the motives constitute the core of the personality. E. Ilyin considers the motivation in close connection with the development of the volitional sphere of a person [3]. H. Heckhausen explains the motivation as a preparatory stage of action in the context of the interaction of a person and a situation [15]. The results of studying motives and motivation are presented in the fundamental research and development of national (V. Aseev, V. Vilyunas, E. Ilyin, A. Leontiev, D. Uznadze) and foreign (A. Maslow, H. Heckhausen, etc.) scientists.

Our contemporaries also do not disregard the problem of motivation and motives. A. Dubnyakova analyzes the main approaches to the study of the professional activity motives, proposes and substantiates the author's classification of the professional activity motives. S. Shabalina investigates the motivation of students 'professional activity in the pedagogical college. N. Zhdanova focuses on the specificities of teachers' professional activity motivation. N. Panova researches motivation in the context of the teacher's personality development. The issues of the formation of engineering-pedagogical specialties students " professional orientation, closely related to the problem of motivation, are disclosed by O. Lnogradskaya [5]. S. Umanets in the monograph offers his own vision of the way of resolving the contradiction between "the current cognitive and informational pedagogical paradigm of higher professional education, for which the natural motivational component of a student's life is not relevant, and the author's evolutionary-ontological concept, in which the natural essence of a human being and the process of his development is prioritized" [13].

Since the problem of motives and motivation by its nature is complex, multifactorial and multidimensional, modern science can hardly offer a universal means of forming the motivation for professional activity.

\section{Methodology}

The purpose of the study is the analysis of the future teachers' extracurricular professionally oriented activities as a factor of forming their professional motivation.

The empirical source of this research is the creation and organization of special professionally oriented activities for future teachers as an upbringing part of their vocational education.

Research concept and methodology. Our research concept is based on the hypothesis that the extracurricular activities of students (future teachers) are one of the factors that have a definite impact on the formation of their professional motivation. 
Research methods are the observation and individual surveys, the analysis of the scientific pedagogical and psychological literature, oral individual interviews and group conversations. On the way towards achieving the purpose, the following tasks were solved: with the help of the observation and individual surveys the attitude of students to their future profession and extracurricular activities was determined; the scientific pedagogical and psychological literature corresponding to the research problem was analyzed; the technology of forming a creative future teacher personality was used for attracting students and organizing their extracurricular professionally oriented activities; oral individual interviews and group conversation were used to determine and justify the effectiveness of extracurricular activities.

The analysis of psychological and pedagogical literature defines that there is no single comprehensive definition of the professional motivation. Different scientific schools interpret the essence of the motivation in their own way. V. Vilyunas argues that the motivation is a set of processes that inspire and lead to action, and A. Platonov considers the motivation as a mental phenomenon - the combination of motives [9]. In our research we interpret the motivation as "a set of persistent motives, interests, impulses that determines the content, direction and nature of a person's activity and person`s behavior" [10].

The research was carried out in two stages.

\section{Results}

At the first stage of the research the observation and individual surveys were fulfilled, and the results indicate that the future teachers have practically low motives for professional pedagogical activity (only 15\%).

I. Gladkaya, analyzing extracurricular activities as a factor of future teachers` professional training, demonstrates different approaches to understanding the essence of this notion. Some teachers equate the concepts of "extracurricular work" and "extracurricular activities", others share these concepts, emphasizing certain authority in the use of the term "work" compared to the concept "activity", which is more consistent with the personality-oriented pedagogical paradigm [2].

It seems to us that "extracurricular activity" is a pedagogically expedient students' activity aiming at future teacher personality`s forming and developing for his / her selfrealization by making up for deficits of learning and upbringing. In the process of creating and organizing extracurricular activities, it is advisable to take into account and focus on students 'interests, inclinations, needs and capabilities. In addition, high school teachers and tutors are recommended not to forget J. Locke's idea that the art of a teacher is making attractive for a student those things that are useful for him. Professionally oriented extracurricular activity is a necessary component of future teachers` professional training, but it does not mean that the teacher's understanding of its necessity will be shared by students to the same extent. Moreover, as we noted earlier, very often future teachers (for example, future specialists in labor protection, information and computer technology, economics and management), even at undergraduate courses, have practically low motives for professional pedagogical activity. The identification of the causes of the current situation is the task of another research project.

O. Lnogradskaya, researching the phenomenon of the engineering-pedagogical specialties students` professional orientation, notes that only a fifth of students who choose these areas of training intends to take teaching job in the future [5]. Her findings coincide with the results of our research of future foreign language teachers' professional motivation, which we conducted during several years earlier. The conclusion is that the social prestige of teaching after the "failure" in the 1990s is being restored extremely 
slowly. As another factor of significant influence on future teachers' professional motivation can be considered the fact that a special (learning) component of teacher training traditionally prevails over pedagogical (upbringing) aspects in a "classical" university.

The second stage of the research is devoted to the creation and organization of future teachers' special professionally oriented activities and the following analysis of the professional motivation level and the level of readiness to fulfill their professional functions.

To eliminate the existing misbalance in the engineering and pedagogical personnel's professional training, students of the Donetsk National University annually take part in the Republican Olympiad in Pedagogy with international participation. The process of involving students in extracurricular professionally oriented activities was quite complicated. It was necessary to convince the students of the expediency of this type of activity, of its usefulness for each of them personally. With the help of the Faculty Student Union's activists and due to individual conversations with the students, the candidates to the Olympiad team were individually selected by special team-tutors (they were the teachers-volunteers from the Department of Pedagogy). The participants agreed to try just out of curiosity to something new and out of respect to their teachers. Nevertheless, the actual interest and motivation of the Olympiad team members towards this type of extracurricular activity was rather low - we can confirm this fact from the team-tutor's point of view.

Traditionally, in the Donbass before the beginning of the civil war in Ukraine in 2014, the Olympiads in Pedagogy consisted of three stages: a theoretical creative written essay, the defense of scientific work and a practical task that proposed to the participants to conduct a fragment of a lesson or an educational event. I. Gladkaya describes the traditional Olympiad in Pedagogy, organized by the colleagues from St. Petersburg, which also includes three stages: a written home essay, the work with a case, the demonstration of a lesson and the reflection on the results of the school working day [2]. The organizers of the Republican Olympiad in Pedagogy in the Donetsk People's Republic have created an alternative model. It is caused - on the one hand - by the difficulties of the political, social and economic situation, in which Donbass has already been for the seventh year. On the other hand - the Donetsk Republic Olympiad reflects the competence approach to the professional teachers 'training and the holistic approach that focuses on the organic link of learning and upbringing based on the main principles of A.S. Makarenko and V.A. Sukhomlinskiy`s pedagogy.

The slogan "Doing good is our way!" has become the motto of the Olympiad that implies the strengthening of the practical orientation for the participants' activity. This model allows to fulfill not only educational tasks defined by the State Educational Standards, but also to solve associated social problems: the popularization of teaching jobs and the provision of volunteer assistance to the residents of the region. These reference points explain the fact that in the motto of the event there is no direct pedagogical component, it can be found only in the practical content of the Olympiad. This situation contains an element of intrigue for the participants (something new, unusual and even unexpected in comparison with the previous traditional Olympiads in Pedagogy) that stimulates their interest, attention and activity. It should be also noted that the Olympiad is in fact a distance project on the online-platform that provides an opportunity to increase the number of national and international teams and in consequence - to make the event more competitive. Simultaneously the distance form allows to reduce the participants 'material costs for taking part in the Olympiad.

The first stage of the Olympiad supposes the team-presentation developing in the form of virtual "business cards". The main task is to represent your future teaching job in the 
most interesting, non-standard creative way, to make a video clip with the team's performance (the period is limited to 5 minutes). Moreover, the content of the team's presentation is to correlate with the motto of the Olympiad, its pedagogical and volunteer orientation and to unleash the creative potential of each member of a team-participant. The fulfillment of the first Olympiad task considerably intensifies the students' interest to the event and their creative activity, makes them look at the future profession from an unusual point of view and turn to special literature and the Internet for additional information, integrate existing knowledge and experience in the field of pedagogy and information and computer technology. The need to complete the assignment expands the horizons of the students ' pedagogical universe, taking them beyond the daily routine, strengthening their inspiration for future teaching job and the desire to act, to make progress and to win the Olympiad. At the first stage of the Olympiad we actually have observed the occurrence of professional motivation. The students have become well-concentrated and self-motivated, have understood the goals and tasks facing them.

The second stage of the Olympiad is theoretical. It includes the online testing of special pedagogical knowledge: the participants are to answer 50 questions in a limited period of time. The list of special literature for preparing to the second stage is previously agreed between the Olympiad jury and team tutors. The students have developed a desire to cope with the tests as best as possible: the need for knowledge, self-actualization [8], the necessity to test and analyze the level of their knowledge and readiness for pedagogical activity have appeared. The students have realized the personal sense of participation in the Olympiad as the possibility of the assessment of their skills and forces. As an additional result of this stage we have also got the increase of the students' professional motivation to future teaching job.

The third stage suggests the preparation and holding of a volunteer pedagogical action. Each team has preferred to demonstrate the specific characteristics of its teaching job specialty. With the help of team-tutors the participants have chosen the theme of the action. The future pre-school teachers and primary school teachers have organized the educational events devoted to Russian decorative and applied art and have conducted them for the kindergarten and primary school children. The heroes of Russian folk fairy-tales have come to the first graders and schoolchildren and told about folk crafts, have taught the children to draw folk ornaments in different styles and technics. The future secondary school teachers have organized the excursions to the places of Labor Glory in Donetsk for the secondary school students. The future high school teachers together with the team-tutor and other students have fixed the places of Donbass defenders 'military burial sites up. The future computer science teachers have organized the master classes in information technology for the beginners. The last stage of the Olympiad implies the manifestation of the participants' ability to share their knowledge and experience with the others. In fact, this coincides with one of the traditional Olympiad tasks - the conducting a lesson or an educational event, that enables the participants to demonstrate the level of the professional competence they have achieved.

At the third stage the future teachers have demonstrated: an adequate critical thinking level in setting the goals and in choosing and justifying the content of their volunteer pedagogical activity; a good level of the ability to work in a team (to hear and to listen to each other, to communicate with various partners, to take or to choose an optimal decision); a high level of creative project activity. As a result - the students have understood social significance of pedagogical activity and the important role of teaching job in the society.

Since the motivation for activity can be considered as a system "of internal motivating elements of a person, such as needs, interests and values, and - of the external environment factors" [11], we can summarize that the Donetsk National University students' participation in the Republican Olympiad in Pedagogy has been at first an external 
environment factor but the appeared professional interest of future teachers in the content of the Olympiad stages has transformed the external factor into an internal one. The conducted surveys show that almost all the members of the Olympiad team have got interested in extracurricular professionally oriented activities (in fact, 100\%); the same answers we have got from the majority of the students who helped the team in preparing for the Olympiad stages (57\%) (Fig. 1).

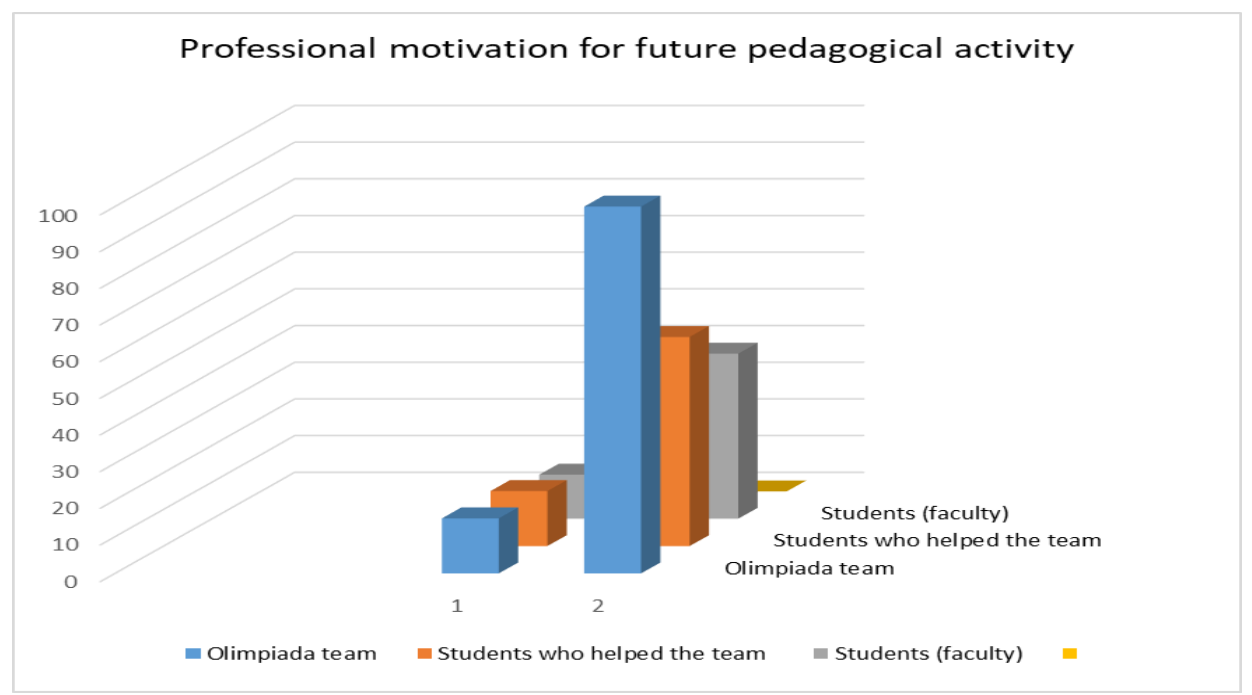

(1 before Olympiad; 2 after Olympiad)

Fig. 1. Professional motivation for future pedagogical activity

However, the professional motivation for future pedagogical activity has arisen only in $30 \%$ of the students who were directly or indirectly involved in the preparation and participation in extracurricular professionally oriented activity.

\section{Conclusion}

The reflection after the event is an obligatory part of the educational process. The students and the team-tutor have gathered to discuss the results of the Olympiad (the second place), to search the answers to some questions: what worked out and why; what did not work and why; what was not enough for us to get a better result and to win; what we need to do to improve the situation the next year. Together with the students we solved "the problem of realizing of the personal sense" [4] and significance of extracurricular professionally oriented activities. As our further experience shows, it has changed the attitude of the future teachers to such activities. After the Olympiad the students have begun to show initiative and activity in defining the content and forms of their own extracurricular activities, to approach the teachers instructions more responsibly, to take a direct part in various types of extracurricular activities more willingly.

Summing up we should note that the use of only one type of extracurricular professionally oriented activities cannot serve as a universal means of forming future teachers' professional motivation. We suppose that the organization of students' extracurricular activities should be based on the following principles: humanization of pedagogical activity, its social pre-conditioning and orientation, complexity, scientific nature, creative activity and self-development. This approach allows to consider the extracurricular activity as a component of the professional teacher training. 
The future students 'extracurricular activities establish the preconditions for sustained professional motivation and "provide ample opportunity for forming such a key professional competence as the readiness and the ability to self-development and creative self-realization" [14]. The results of our study make it possible to assert that the creative approach, non-standard content and forms of future teachers` extracurricular activities function as an important catalyst in the formation of professional motivation.

\section{References}

1. Interview with V.V. Putin, https://www.1tv.ru/news/2018-12 -20 / 357610vladimir_putin_nam_nuzhen_proryv_nuzhno_prygnut_v_novyy_tehnologicheskiy_ukl ad_bez_etogo_u_strany_net_buduschego (Last accessed 12.07 .2020 )

2. O. Fedotova, P. Pivnenko, World Applied Sciences Journal, 31(2), 176-181 (2014) Doi 10.5829/idosi.wasj.2014.31.02.14294

3. R. Jimenez-Fontana, L. Aragon, G. Albendin, Revista eureka sobre ensenanza y divulgacion de las ciencias, 17(3), (2020) Doi 10.25267/Rev_Eureka_ensen_divulg_cienc.2020.v17.i3.3203

4. R. Soares, et al., Revista praxis educacional, 16(40), 573-591(2020) Doi 10.22481/praxisedu.v16i40.6446

5. C. Pereira, T. Lopes, C. Garcia, Comunicacoes, 27(2), 193-214 (2020) Doi 10.15600/2238-121X/comunicacoes.v27n2p193-214

6. M. Lo, Teaching And Teacher Education, 32(6), 910-926 (2019) Doi 10.1016/j.tate.2019.01.005

7. J. Lofgren, O. Pavlov, F. Hoy, Springer Proceedings in Business and Economics, 5360 (2018) Doi 10.1007/978-3-030-04726-9_6

8. S. Popova, N. Rozov, Russian education and society, 54(11), 65-79 (2012) Doi 10.2753/RES1060-9393541105

9. J. Aber, et al., Journal of research on educational effectiveness, 9(3), 334-363 (2016) Doi 10.1080/19345747.2015.1107925

10. I. Grassler, P. Taplick, X. Yang, Proceedia CIRP, 54, 141-146 (2016) Doi 10.1016/j.procir.2016.05.103

11. M. Fleer, Learning culture and social interaction, 24, (2020) Doi 10.1016/j.lcsi.2019.100355

12. I. Skakni, Studies in graduate and postdoctoral education, 9(2), 197-212 (2018) Doi 10.1108/SGPE-D-18-00004

13. R. Wright, Motivation and emotion, 40(1), 16-21 (2016) Doi 10.1007/s11031-0159536-4

14. M. Thielgen, Journal of career assessment, 23(3), 459-480 (2015) Doi $10.1177 / 1069072714547613$

15. O. D. Fedotova, O. P. Chigisheva, International Perspectives on Education and Society, 26, 57-82 (2015) Doi 10.1108/S1479-367920140000026003

16. L. Cohen, L. Manion, K. Morrison, Research methods in education. 7th edition. Routledge, NY (2011)

17. J. Freeman, S. Walters, M. Campbell, How to display data (Blackwell Publishing, Massachusetts, USA, 2008) 